\title{
Learners' Perception of Differences between Language Learning in High School and Private Language Institute
}

\author{
Mehdi Davari Torshizi (Corresponding author) \\ Payame Noor University of Kashmar, Iran \\ E-mail: mdavari61@yahoo.com \\ Marzieh Davari Torshizi \\ University of Shahrood, Iran \\ E-mail: mdavari_t@yahoo.com
}

\begin{abstract}
Received: 14-05-2015
Accepted: 24-08-2015

Advance Access Published: October 2015

Published: 01-01-2016

doi:10.7575/aiac.ijalel.v.5n.1p.33

URL: http://dx.doi.org/10.7575/aiac.ijalel.v.5n.1p.33
\end{abstract}

\begin{abstract}
This study aims at examining the differences between learning English as a Foreign Language (EFL) in high school (formal context) and private language institute (informal context) from learners' perspective. To this end, language learners who were simultaneously studying in both contexts in Mashhad, Iran were selected and interviewed to elicit accurate and complete responses to the research question. Grounded Theory (GT) approach was used to carry out the study. Accordingly, data collection and analysis continued until theoretical saturation was reached. Data analysis revealed that due to 'inappropriate placement', 'disproportionate number of students', 'simple and ordinary teaching method' and 'grade oriented environment', high school learners were less motivated in comparison to private institute learners. The paper provides policymakers with a window into developing the process of language learning in high schools and further research on problems in EFL education system in both public schools and private language institutes.
\end{abstract}

Keywords: High school, Private language institute, Context, Grounded Theory

\section{Introduction}

Language learning in Iran takes place in both formal and informal contexts. Differences between these two contexts are easily observable and its effects, then, on the process of language learning are inevitable. Considering differences between language learning in public high schools and private language institutes raised the cardinal questions of how learners, who are experiencing these two contexts simultaneously, perceive these two different contexts, how they adapt themselves to each setting and what their beliefs and expectations are. Review of literature showed that studies carried out into this particular subject are limited. Therefore, to conduct the study, the researcher entered the field to investigate participants' conceptions and beliefs on this issue. To this end, developing Grounded Theory approach, participants were interviewed and data were analyzed so as to see "what is going on" (Glaser, 2002, p. 22).

It is argued that the beliefs and conceptions of individuals shape their actions and lead them to their aims. A vast body of research has been conducted in the area of language learning which has produced remarkable findings about the effect of individuals' beliefs on L2 learning. Cognitive oriented studies, for example, considered beliefs as "an internal autonomous property of the mind" (p. 234) which are formed and constructed either in social contexts or as an autonomous individual act (Gabillon, 2002). Further, a pioneering study conducted by Horwitz (1999) demonstrated that learners' belief is influential in both their actions and experiences. Abedini, Rahimi and Zare-ee (2011) also found that Iranian EFL learners' belief affects their strategies used for language learning and it also has significant effects on language proficiency. Hence, it is tempting to conclude that learners' beliefs occupy a special place in our understanding of their experiences of language learning procedure.

Upon reviewing the research on differences between language learning in high school and private institute contexts in Iran, we are left with persuasive evidences of contextual deficiencies in high schools. For instance, by taking parents' confidence in institutes for learning a foreign language into account, Ghaffarzadeh Hassankiadeh (2013) reported that school materials and text-books shortages, learners' different desires, teachers' limitation and some other problems were the cause of high schools failure in teaching/learning a foreign language in comparison to private institutes. Furthermore, Pishghadam and Navari (2010) took one of the first steps toward examining language learners' perception of learning conditions in Iran and remarked that the language learning process in high schools took place in a predominantly behavioristic environment. The study also revealed that class decisions were mostly made by teachers who authoritatively held the classes while institute learners conceptualized teachers' role to be facilitative in the learning process and the institute environment to be situational in comparison to traditional type of high school environment (Pishghadam \& Navari, 2010). Likewise, in a different region with different culture in Iran, Assadi 
Aidinlou, Farjami and Javidan (2014) echoed the findings of earlier study by Pishghadam and Navari (2010) and reported somehow consistent results.

Furthermore, it seems reasonable to assume that these findings are inextricably interwoven with motivational and demotivational factors which have a profound effect on learners' achievement. Scholars have given different definitions of motivation. Brown (2007), for instance, provides a captivating description of motivation: "Undoubtedly the most frequently used catch-all term for explaining the success or failure of virtually any complex task, motivation is a star player in the cast of characters assigned to second language learning scenarios around the world" (p. 168). The role of this player has captured researchers' attention in the field of second and foreign language acquisition (Bernard, 2010; Cheng \& Dörnyei, 2007; Csizér \& Dörnyei, 2005; Dörnyei, 1998, 2000, 2008). Guay defines motivation as "the reasons underlying behavior" (Guay et al., 2010, p. 712). Broussard and Garrison (2004) also ascribe motivation to what moves us to do or no to do something. Motivational belief, too, is noteworthy in that it refers to learners' opinions about the efficiency of learning and teaching methods which are implemented in an educational system. Learners hold these opinions as a result of their direct learning experiences which guide their thinking, feelings and actions in a subject area (Boekaerts, 2002). To offer a definition, motivation can be interpreted as the only fuel which runs the human machine.

Motivation holds its pervasive part in the process of language learning in foreign language situations as well. For instance, by examining the relationship between teaching methodology and motivation in both high school and English private institute context in Iran, Keihaniyan (2011) found a positive relationship between these two factors and remarked that private institute learners' motivation was higher than that of high school learners due to interesting materials provided at institutes and the facilitative role of teachers in comparison to authoritative role of high school teachers. This study also revealed that teachers at institutes give learners an active role which increases their motivation (Keihaniyan, 2011). In addition, Pishghadam and Motakef's (2012) work showed that intrinsic motivation, or dearth of it, has a crucial part in language learners success in language learning procedure regardless of their gender or socioeconomic backgrounds. Moreover, by examining female English students' integrative and instrumental motivation in intermediate level in Ilam, Iran, Aliakbari and Ahmadi (2013) found that students were more motivated after entering language private institutes compared to college and high school students. Some factors addressed by students were exciting and proficient teachers, interesting learning context and better textbooks.

As we have seen, then, these researches and myriad findings of other studies on this issue crystallize the cardinal role of motivation in language learning in EFL context. Of prime importance, therefore, is finding the reasons why learners' motivation waxes and wanes during language learning procedure. For this reason and due to lack of qualitative research into this particular issue and in order to answer some of the questions that cross-sectional questionnaire-based research is unable to answer, face-to-face (FtF) tape recorded interview was selected to carry out the study. Opdenakker (2006) proposed that FtF interview is preferred when the interviewees are seen as irreplaceable subjects whose opinions are salient. He also highlighted the advantages of recorded interview for the accuracy of its results compared to note taking. Furthermore, he remarked that FtF interview provides interviewee with possibility to "create a good interview ambience" or "standardization of situation" (para. 10)

In line with this method of collecting data is the way data is analyzed in a grounded theory (GT) research in a systematic approach in order not to work on assumptions about the research hypotheses as Glaser and Holton (2004) stated:

GT provides an honest approach to the data that lets the natural organization of substantive life emerge. The GT researcher listens to participants venting issues rather than encouraging them to talk about a subject of little interest. The mandate is to remain open to what is actually happening and not to start filtering data through pre-conceived hypotheses and biases to listen and observe and thereby discover the main concern of the participants in the field and how they resolve this concern. (p. 11)

Concerning lack of research on this particular issue, by juxtaposing high school context with private language institute context and implementing GT approach, unlike other related studies, this study took a different procedure to collect and analyze data so as to probe into differences between language learning in these settings in Iran. To improve the accuracy of data, therefore, the study was undertaken at the time in which learners were experiencing language learning simultaneously in both contexts.

\subsection{A brief description of public high school and private language institute settings}

Investigating the changing winds and shifting sands of the history of language learning in these two contexts is beyond the scope of this article, but their language instruction and learning stages are concisely described.

The number of private language institutes dramatically increased in Iran since learning English became a social need and a requirement to meet for job opportunities (Farhady, Sajadi Hezaveh \& Hedayati, 2010). All private language institutes have an almost similar process for accepting learners in Iran. After enrolling, participants are interviewed to know whether they have had any experiences in language learning. The result provides institutes with decision on how to go through the process of level determination. According to the test results, learners are placed in proper classes. Most of the participants are in the 5-20 age range, but classes are also held for adults at any ages.

On the other hand, the Ministry of Education is responsible for educational planning, financing, administration, curriculum, and textbook development for public schools. Teachers are also trained, graded and examined by the Ministry. After finishing Middle (Guidance) Cycle, students enter high school or secondary education cycle which covers grade 9 to 12 from age 14 to 17 . The English courses which students have to take are similar in all schools 
around the country. They consist of four textbooks which are designed and provided by the Ministry of Education.

\section{Methodology}

\subsection{Participants and Setting}

To conduct the study, 12 high school learners, 5 males and 7 females, who were studying in grades 9 to 12, in Mashhad, Iran, were selected. They were from age14to17 and at the intermediate level of proficiency. They were assured that instead of their real names, pseudonyms will be used in the reporting of the data. Considering the aim of this study which was highlighting differences between language learning in public high schools (formal context) and private language institutes (informal context), participants were selected from those learners who were experiencing language learning in both contexts simultaneously -the point which had not been considered in other studies on this issue and was beneficial to improve the accuracy of the data.

\subsection{Data collection}

Unstructured face-to-face interview was used to collect the data. The interview was opened with a general, non-leading question, which is the characteristic of the research question in GT, "What are the differences between language learning in high school and private language institutes?" As the interview was proceeding, participants were asked to clarify the details in order to probe deeper into their initial responses. The process of data collection and data analysis continued until theoretical saturation was achieved. Then, the interviews were transcribed to facilitate the process of coding which was carried out line-by-line to conceptualize the data precisely and accurately. Accordingly, the data were categorized based on their similar units of meanings and the linkages between them were established.

\subsection{Limitation}

The abbreviated version of grounded theory was used in this study in that the time and resource constraints thwarted the implementation of the full version of grounded theory. Therefore, the study can be conducted with a larger number of participants with different ages and in other regions to cast the net more widely and get a broader perspective on the issue.

\section{Results}

In collecting the data, every attempt was made to be methodical and avoid personal biases. Participants' responses to the research question, which should be a non-leading and general one in Grounded Theory, mostly highlighted public high school deficiencies. So, the labels used for each category were chosen accordingly. However, language private institute contexts, obviously, are not devoid of any shortcomings and high school contexts, too, enjoy considerable benefits to language learners.

\subsection{Inappropriate Placement}

English Language Proficiency (ELP) assessment has a crucial role in the classification of language learners. The main criterion, then, for grouping language learners is their level of language proficiency which necessarily determines the proper instruction and instructional materials (Abedi, 2007). Despite its vital importance, ELP assessment has been overlooked in public high schools curriculum in Iran. In public high schools, students are lumped together in one English class regardless of their proficiency levels, but according to their ages. Consequently, in one class, there may be some who have learned English since childhood or some who have just started learning English. The results clearly showed that this is the main reason why students who are at higher levels of proficiency are demotivated in high school English classes. This fact was supported by Fahimeh, one of the participants, who complained:

Most of the students are going to institute classes. The teacher repeats something over and over again for a few who are not going to institutes and are weaker. So, it gets boring for others.

Similarly Ali, another participant, stated:

The rules of grammar are fully taught in the institute and it's more comprehensive. But the teacher has to explain a grammar point, which we have learned before, for other students in the school.

Furthermore, another point related to this category which was stressed by participants was their performances in school examinations. Farzaneh who was taking English classes in a private institute, was eager to share her ideas and clearly stated that she easily passes her school examinations:

I feel more relaxed in the school. Whenever I have an exam, it's so simple that I ace it.

\subsection{Disproportionate Number of Students}

Student-to-teacher and student-to-student interaction are dependent on the host of factors among which time and class size are of utmost importance. Although the exact number of students for each class cannot be statistically determined, class size should be in reasonable proportion to its time. Participants in this study believed that large number of students in high school English classes blocks their interaction with their teachers and classmates. Sarah explained:

In the school, some of my questions remain unanswered and I have to ask my questions after the class.

Sometimes due to shortage of time, teacher puts off answering our questions for the next class.

On the other hand, Reza believed that in institute classes he has enough time to interact with his classmates and ask the teacher to answer his questions. He plainly stated: 
Our teacher in the institute expands on his answers to our questions because the number of students is small and there's enough time to do so. If anything is left vague in your mind, it will be explained clearly for all students even if you ask a question which is not related to the book. I also got better acquainted with my classmates in the institute because we are fewer in number.

Although other factors affect interactions in language classrooms as well, time and class size were mostly mentioned by participants as key factors blocking their interactions in classroom environment.

\subsection{Simple Teaching Methods}

Undoubtedly, myriads of elements should be taken into consideration so as to choose an appropriate method of teaching in a language class, which its discussion is outside the scope of this article, but the results of this study, supported by considerable number of participants, confirmed that teaching methods in high school English classes were ordinary and simple in comparison to the methods implementing in private institute classes. Speaking Persian was one of the factors reasoned by participants. For instance, Mona complained:

Teachers speak too much Persian in school and the vocabulary is limited to our books, but in institutes, teachers speak English and we learn more vocabulary because it's repeated over and over again. We're also encouraged to speak English by teachers.

Furthermore, the other factor which was verified by most of the participants was different textbook design. It could be categorized as a separate finding, but it is presented here since textbook and syllabus design are closely woven into the fabric of teaching method, as McGrath (2006) put it "Course book tend to dictate what is taught, in what order and, to some extent, how as well as what learners learn" (p. 171).

Studies on textbook evaluation in Iran have been conducted by many researchers in the field, but Razmjoo's (2007) work, which is more relevant to this study, is noteworthy in that he analyzed both institute and high school textbooks and showed that there is a sharp difference between two types of textbooks. He demonstrated that high school textbooks are designed without taking students' needs into consideration and they are reading and grammar oriented. However, textbooks used in private institutes cover all skills of the language and represent Communicative Language Teaching (CLT) principles more than high school textbooks.

Differences between high school and institute textbooks were plainly highlighted by participants of this study as well. Different subject of reading texts was the main factor which was indicated by most of the participants. For instance, Sadegh explained:

The subjects of reading in school textbooks are not interesting, but institute textbooks have funnier subjects and our teachers give us interesting topics to write about.

The other factors that accentuated a major difference between textbooks were simple conversations and vocabulary used in high school textbooks. Participants believed that conversations mostly cover greetings and introductions. In contrast, they differentiated institute textbooks for they encompass a broad range of subjects and vocabulary. As evidence, Nahid stated:

The textbooks are ordinary and we learn simple conversations in school like 'hello, how are you?' and the vocabulary are also very easy.

Describing institute textbooks, Hamid explained:

Reading and writing subjects in institute textbooks are interesting and we learn new vocabulary. The grammar rules are also fully taught and conversations are very interesting.

\subsection{Grade-oriented vs. learning-oriented environment}

An important insight to be applied to our understanding of a standard learning environment lies in its orientation toward evaluation. In academia, students and teachers have varied perceptions of grading and evaluating and of its process and policy. Therefore, of utmost importance is considering students' and teachers' expectation of evaluation process, which goes hand in hand with each other, so as to achieve consistency between them. Results of this work, too, stressed the importance of orientation of learning environment and confirmed that it occupies a pivotal role in students' motivation. The study demonstrated that learners were more motivated in a learning-oriented environment in contrast to a gradeoriented one. Participants verified that one of the reasons why they attend high school English classes is that they have to attain the required grade in order to pass their English examinations whereas they willingly participate in institute classes and are more motivated to do so. For example, Nafiseh commented:

I attend high school classes just for grading. I only study to achieve grades, but in institute classes you don't lose grades and you study to learn not to get grades. 
Describing private institute environment, Zahra stated:

I attend institute classes freely and enthusiastically. It's not obligatory, so I think it's more influential

in learning. Besides, we don't study to get a grade but to learn.

Obviously, determining the orientation of learning in an educational system necessitates a detailed and painstaking research into a plethora of aspects affecting its environment. This category, then, was the result of rigorous analysis and interpretation of data which gave rise to this label according to similar units of meaning and words such as 'grade', 'learning', 'willingly', 'obligatory' and 'enthusiastically' used by most of participants in the interviews.

\section{Discussion and Conclusion}

It was the main purpose of this work, by implementing Grounded Theory approach, to examine the differences between language learning in both private language institute and public high school contexts from Iranian English learners' perspective. They were experiencing both contexts simultaneously, which is a significant factor that has not been considered in other studies on this issue. The study, then, addresses the effects of these differences on the process of learning and learners' performances. Results revealed that, 'inappropriate placement', 'disproportionate number of students', 'simple and ordinary teaching method' and 'grade oriented environment' are shortcomings in high schools context and as a result, the reasons why learners are less motivated.

First and foremost, the findings of this work underscore the importance of placement, which is the core category of this study, in any language instruction and show its decisive effect on learners' performances, evaluation and motivation in general. Considering inappropriate placement in public high schools in Iran, it can be concluded that striking a balance in teaching learners whose proficiency levels are different in one English class seems next to impossible unless the teacher waves a magic wand to do the trick. Furthermore, it results in learners' demotivation and deficiencies in their evaluation because learners with high level of proficiency are more likely to pass their examinations easier than other learners. In addition, findings present the point that the large number of students in English classes and grade-oriented environment are demerits of high school context which the former exerts negative effects on learners' interactions in the classroom environment and the latter have adverse influences upon students' motivation. However, assuming that a grade-oriented environment has always negative consequences for language learning and teaching raises some caution flags because it necessarily requires further research to investigate its broad aspects on the whole.

Another finding emerged from data interpretation is simple and ordinary teaching method in high schools, which is in good agreement with Pishghadam and Navari's (2010) study which has shown that high schools environment are traditional in comparison to situational type of institutes environment. However, unlike this study, their work examined high school English learners who had no experience of language learning in private institutes.

Moreover, this paper provides us with the effects of textbook and syllabus design on teaching method which seem inevitable. In other words, taking a language instruction syllabi and textbooks into consideration in order to determine its teaching method is of paramount importance in that they are inextricably intertwined. Thus, teachers are reminded of their need to be judicious in selecting appropriate methods to be compatible with learners' needs and expectations and more importantly with textbooks. It is also noteworthy that although results of this study, similar to Razmjoo's (2007) work, support the inappropriateness of high school textbooks, syllabus design and the evaluation of textbooks in both contexts need to undergo carful and detailed scrutiny since it occupies a discrete and special place in the field of language learning and teaching in general.

Two distinct educational contexts, public high school (formal) and private language institute (informal), with common aims of teaching foreign languages have been provided for language learners in Iran. Despite their common objectives, they are using dissimilar procedure for teaching and learning English which gives rise to a host of problems. Further research, then, might be of help to explore and address the growing problems caused by inconsistency between two settings. Moreover, considering the results of this study, it behooves educational policy makers to formulate a plan to ameliorate and promote learning and teaching of English in public high schools which necessarily needs a separate curriculum planning regardless of other courses. Of greatest importance, too, is making an accommodation between public high schools and private language institutes educational system which forms the foundation stones for building a fruitful language instruction and augments the effectiveness of both contexts under these circumstances.

\section{References}

Abedi, J. (Ed.). (2007). English language proficiency assessment in the nation: Current status and future practice (pp. 310). University of California, Davis, School of Education.

Abedini, A., Rahimi, A., \&Zare-ee, A. (2011). Relationship between Iranian EFL learners' beliefs about language learning, their language learning strategy use and their languageproficiency. Procedia-Social and Behavioral Sciences, 28, 1029-1033.

Aliakbari, M., \& Ahmadi, S. (2013). English Learning Motivation: the case study of Female Students in Ilam, Iran.International Journal of Psychology and Behavioral Research. Vol., 3(6).

Boekaerts, M. (2002). Motivation to learn. International Academy of Education. Leiden University, Netherlands. 
Broussard, S. C., \& Garrison, M. E. B. (2004). The relationship between classroom motivation and academic achievement in elementary school-aged children. Family and Consumer Sciences Research Journal, 33(2), $106-120$.

Brown, H. Douglas. (2007) principles of language learning and teaching. $5^{\text {th }}$ ed. the United States of America: Pearson Education, Inc.

Bernard, J. (2010). Motivation in foreign language learning: The relationship between classroom activities, motivation, and outcomes in a university language-learning environment. A published thesis, University of Carnegie Mellon, Pittsburgh, USA.

Cheng, H.-F., \&Dörnyei, Z. (2007). The use of motivational strategies in language instruction: The case of EFL teaching in Taiwan. Innovation in Language Learning and Teaching, 1(1), 153-174

Csizér, K., \&Dörnyei, Z. (2005). Language learners' motivational profiles and their motivated learning behaviour. Language Learning, 55(4), 613-659.

Dörnyei, Z. (1998). Motivation in second and foreign language learning.Language teaching, 31(03), 117-135.

Dornyei, Z. (2000). Motivation in action: Towards a process-oriented conceptualisation of student motivation. British Journal of Educational Psychology, 70(4), 519-538.

Dörnyei, Z. (2008). New ways of motivating foreign language learners: Generating vision. Links, 38, 3-4.

Farhady, H., Hezaveh, F. S., \&Hedayati, H. (2010). Reflections on Foreign Language Education in Iran. TESLEJ, 13(4), n4.

Glaser, B. (2002). Conceptualization: On theory and theorizing using grounded theory. International Journal of Qualitative Methods, 1 (2). Article 3. Retrieved DATE from http://www.ualberta.ca/ ijqm/

Glaser, B. G., \& Holton, J. (2004). Remodeling grounded theory. In Forum Qualitative Sozialforschung/Forum: Qualitative Social Research .Vol. 5, No. 2.

Gabillon, Z. (2005). L2 learner's beliefs: An overview. Journal of Language and Learning, 3(2), 233-260.

McGrath, I. (2006). Teachers' and learners' images for coursebooks. ELT journal, 60(2), 171-180.

Guay, F., Chanal, J., Ratelle, C. F., Marsh, H. W., Larose, S., \&Boivin, M. (2010). Intrinsic, identified, and controlled types of motivation for school subjects in young elementary school children. British Journal of Educational Psychology, 80(4), 711-735.

Horwitz, E. K. (1999). Cultural and situational influences on foreign language learners' beliefs about language learning: A review of BALLI studies. System,27(4), 557-576.

Keihaniyan, M. (2011). Teaching methodology and motivation: Comparison of Iranian English private institute and high school. Journal of Language Teaching and Research, 2(3), 588-599.

Alsadat, M., \&Hassankiadeh, G. (2013). Schools V.S Institutes In Learning a Foreign Language: For Iranian EFL Learners.International Journal of Language and Linguistics. Special Issue: Language Teaching and Learning Key Principles (LTLKP).Vol. 1, No. 4-1, 40-47.

AssadiAidinlou, N., Farjami, F., RezaeeJavidan, A. (2014). Iranian High School Students' Beliefs about Language Learners: AQualitative Study. International Journal of Language and Linguistics. Special Issue: Foreign Language Teaching and Learning (Modelsand Beliefs). Vol. 2, No. 3, 21-31.

Opdenakker, R. (2006). Advantages and disadvantages of four interview techniques in qualitative research. In Forum Qualitative Sozialforschung/Forum: Qualitative Social Research . Vol. 7, No. 4).

Pishghadam, R. (2010). Examining Iranian Language Learners Perceptions of Langauge Education in Formal and Informal Contexts. The modern journal of applied linguistics, 2.

Pishghadam, R., \&Motakef,R. (2012). Attributional Analysis of Language Learners at High Schools: A Case of Iranian Learners. Iranian Journal of Applied Linguistics, 15.

Razmjoo, S. A. (2007). High schools or private institutes textbooks? Which fulfill communicative language teaching principles in the Iranian context. Asian EFL Journal, 9(4), 126-140. 